\title{
Evaluación del método dilución neutralización aplicado a un desinfectante según la Norma Técnica Colombiana 5473 de 2007
}

\author{
Janeth Arias-Palacios ${ }^{1 *}$, Libardo Hernandez-Esquivel², Juan Carlos Marín-Díaz ${ }^{3}$, \\ Natalia Navarro-Peña ${ }^{3}$, Natalia Santos-Arévalo ${ }^{3}$ \\ ${ }^{1}$ Grupo de Biotecnología Ambiental e Industrial (GBAI). Departamento de Microbiología, Facultad de Ciencias. \\ Pontificia Universidad Javeriana, Bogotá, D.C., Colombia. \\ ${ }^{2}$ Laboratorios Vicar Farmacéutica. Bogotá, D.C., Colombia. \\ ${ }^{3}$ Carrera de Microbiología Industrial. Facultad de Ciencias. Pontificia Universidad Javeriana, Bogotá, D.C., Colombia. \\ *jdcarias@javeriana.edu.co
}

Recibido: 27-09-2011; Aceptado: 28-02-2012

\begin{abstract}
Resumen
Objetivo. Evaluar el método de dilución neutralización propuesto en la Norma Técnica Colombiana 5473 de 2007, mediante la utilización de un desinfectante en gel a base de alcohol. Materiales y métodos. El ensayo se efectuó utilizando Pseudomonas aeruginosa ATCC 15442, Staphylococcus aureus ATCC 6538 y Enterococcus hirae ATCC 10541, como microorganismos de ensayo. Las temperaturas del estudio fueron $20 \pm 1^{\circ} \mathrm{C}$ como temperatura obligatoria y $36 \pm 1^{\circ} \mathrm{C}$ y se emplearon cuatro tiempos de contacto entre el desinfectante y los microorganismos evaluados (0, 2, 5 y 10 minutos). El método fue realizado bajo condiciones limpias ( $0,3 \mathrm{~g} / \mathrm{L}$ de albumina de suero bovino) y sucias ( $3 \mathrm{~g} / \mathrm{L}$ de albumina de suero bovino y $3 \mathrm{~g} / \mathrm{L}$ de eritrocitos de oveja). Resultados. La implementación del método arrojó resultados precisos en cada una de las seis repeticiones realizadas en el ensayo. Los resultados obtenidos demostraron una reducción logarítmica superior a cinco, evidenciando la actividad bactericida ejercida por el desinfectante frente a los microorganismos control. El establecimiento de las condiciones experimentales y de la metodología demostró no incidir negativamente en el crecimiento de cada una de las cepas. Igualmente, el neutralizante utilizado no inhibió el desarrollo de los organismos de ensayo. Conclusiones. Se verificó el método mediante el cumplimiento de los límites establecidos por la norma. Los resultados sugieren que el método evaluado mediante la implementación del protocolo establecido en la Norma Técnica Colombiana 5473 de 2007, permite evaluar la eficacia de un desinfectante bajo condiciones experimentales escogidas y controladas.
\end{abstract}

Palabras clave: desinfección, condiciones limpias, condiciones sucias, método dilución neutralización, reducción logarítmica.

\begin{abstract}
Assessment of the dilution-neutralization method with a disinfectant according to the Colombian Technical Norm 5473 of 2007. Objective. Evaluate the dilution-neutralization method proposed in the Colombian Technical Norm 5473/07, by using a gel, alcoholbased disinfectant. Materials and methods. This study was done using Pseudomonas aeruginosa ATCC 15442, Staphylococcus aureus ATCC 6538, and Enterococcus hirae ATCC 10541 as the assay microorganisms. The study was carried out at $20 \pm 1^{\circ} \mathrm{C}$ as obligatory temperature and additionally at $36 \pm 1{ }^{\circ} \mathrm{C}$. Four contact times between microorganisms and the disinfectant were evaluated $(0,2,5$ and 10 minutes). The assay was done both under clean conditions ( $0.3 \mathrm{~g} / \mathrm{L}$ of bovine serum albumin), and unclean conditions ( $3 \mathrm{~g} / \mathrm{L}$ of bovine serum albumin and $3 \mathrm{~g} / \mathrm{L}$ of sheep erythrocytes). Results. The implementation of this method produced precise results in all of the six repetitions used during the assay. The obtained results demonstrated a logarithmic reduction higher than five, demonstrating the bactericidal activity exerted by the disinfectant on the control microorganisms. The established experimental conditions and methodology did not affect negatively the growth of any of the strains of microorganisms. Similarly, the neutralizing used did not inhibit the development of the microorganisms of the assay. Conclusions. The method was verified by means of the fulfillment of the limits set by the rule. Our results suggest that the method evaluated by means of the implementation of the protocol established in the Colombian Technical Norm $5473 / 07$, allows evaluating the effectiveness of a disinfectant under selected and controlled experimental conditions.
\end{abstract}

Key words: disinfection, clean conditions, unclean conditions, dilution-neutralization method, logarithmic reduction. 


\begin{abstract}
Resumo
Avaliação do método de diluição-neutralização aplicado num desinfectante segundo a "Norma Técnica Colombiana 5473 de 2007'. Objetivo. Avaliar o método de diluição-neutralização proposto na "Norma Técnica Colombiana 5473 de 2007”, pela utilização de um desinfectante gel à base de álcool. Materiais e métodos. O teste foi realizado utilizando Pseudomonas aeruginosa ATCC 15442, Staphylococcus aureus ATCC 6538 e Enterococcus hirae ATCC 10541, como microrganismos de ensaio. As temperaturas do estudo foram de $20 \pm 1{ }^{\circ} \mathrm{C}$ como temperatura requerida e $36 \pm 1{ }^{\circ} \mathrm{C}$ e foram utilizados quatro tempos de contacto entre o desinfectante e os microorganismos avaliados (0,2,5 e 10 minutos). O método foi realizado sob condições limpas ( $0,3 \mathrm{~g} / \mathrm{L}$ de albumina sérica bovina) e sujas ( $3 \mathrm{~g} / \mathrm{L}$ de albumina sérica bovina e $3 \mathrm{~g} / \mathrm{L}$ de eritrócitos de carneiro). Resultados. A implementação do método produz resultados precisos sobre cada uma das seis repetições realizadas no ensaio. Os resultados mostraram uma redução logarítmica superior a cinco, o que evidencia a actividade bactericida exercida pelo desinfectante contra os microrganismos control. O estabelecimento das condições experimentais e da metodologia provou não incidir negativamente no crescimento de cada uma das cepas. Similarmente, o neutralizador utilizado não inibiu o desenvolvimento dos organismos do experimento. Conclusões. Verificou-se o método através do cumprimento dos limites estabelecidos pela norma. Os resultados sugerem que o método avaliado através da aplicação do protocolo estabelecido pela “Norma Técnica Colombiana 5473 de 2007”, permite avaliar a eficácia de um desinfectante em condições experimentais seleccionadas e controladas.
\end{abstract}

Palavras-chave: desinfecção, condições limpas, condições sujas, o método de diluição-neutralização, redução logarítmica.

\section{Introducción}

El control microbiano en el área de la salud, constituye actualmente, uno de los pilares para la implementación de procesos que garanticen la seguridad a pacientes y personal que labora en el área. Por ello, la limpieza y la desinfección son el mecanismo principal al cual se debe acudir si se quiere mantener un ambiente libre de microorganismos que pueden llegar a alterar la salud de pacientes y personal asistencial (1)

La desinfección efectiva requiere control y monitoreo de todas la etapas del proceso. Los procesos de limpieza, desinfección y esterilización tienen como propósito remover o destruir microorganismos. La selección del método de limpieza y desinfección depende del riesgo de infección asociado con el uso del objeto a desinfectar. Esto también depende de la disponibilidad de método, del tiempo necesario para el proceso y de la naturaleza del objeto, por ejemplo su tolerancia al calor, a la humedad y a los agente químicos (2) Los desinfectantes son agentes que eliminan microorganismos pero no necesariamente sus esporas y no deben aplicarse sobre tejidos sino sobre objetos inanimados, en contraste, los antisépticos son agentes microbicidas que pueden aplicarse sobre la piel y mucosas pero no pueden ser utilizados internamente (3)

\section{Materiales y métodos}

\section{Preparación de los cultivos de trabajo}

Se prepararon tres pases de los microorganismos de ensayo en agar TSA, incubando cada uno durante 24 horas a $37^{\circ} \mathrm{C}$, a partir del tercer pase se elaboró la suspensión de ensayo transfiriendo asadas de células a un frasco schott con $300 \mathrm{ml}$ de solución salina. Se agitó con vortex y se midió la absorbancia a longitud de onda de $540 \mathrm{~nm}$. Se prepararon diluciones $10^{-6}$ y $10^{-7}$ y se sembraron por duplicado en agar TSA, utilizando la técnica de vertido en cajas. A partir de la dilución $10^{-5}$ de la suspensión de ensayo, se preparó la suspensión de validación diluyéndola una cuarta parte. De esta suspensión se preparó una dilución $10^{-1}$ y se sembró por duplicado en agar TSA. Todas las cajas se incubaron durante 24 horas a $37^{\circ} \mathrm{C}$ y se realizaron los respectivos recuentos.

\section{Establecimiento de las condiciones experimentales}

El ensayo se efectuó empleando una temperatura obligatoria de $20^{\circ} \pm 1^{\circ} \mathrm{C}$ y una adicional de $36^{\circ} \pm 1^{\circ} \mathrm{C}$. Los tiempos de contacto entre el desinfectante y las cepas estudiadas se ajustaron mediante un ensayo preliminar, teniendo en cuenta las condiciones reales de uso del desinfectante evaluado, alcohol glicerinado al $65 \%$. De esta forma, se implementaron los siguientes tiempos: 0, 2, 5 y 10 minutos. El ensayo se realizó bajo condiciones limpias $(0,3 \mathrm{~g} / \mathrm{L}$ de albúmina de suero bovino) y bajo condiciones sucias simuladas $(3 \mathrm{~g} / \mathrm{L}$ de albúmina de suero bovino y $3 \mathrm{~g} / \mathrm{L}$ de eritrocitos de oveja), siguiendo las especificaciones de la norma. Los microorganismos evaluados fueron Pseudomonas aeruginosa ATCC 15442, Staphylococcus aureus ATCC 6538 y Enterococcus hirae ATCC 10541, establecidos en la norma.

\section{Implementación del método}

Se pipeteó $1 \mathrm{ml}$ de la sustancia interferente en un tubo y $1 \mathrm{ml}$ de la suspensión de ensayo. Se mezcló y se colocó 
en un baño de agua a la temperatura seleccionada durante $2 \mathrm{~min}$. Se añadieron $8 \mathrm{ml}$ de producto y luego de mezclar se colocó el tubo en un baño de agua a la temperatura y el tiempo seleccionados. Se tomó $1 \mathrm{ml}$ de esta mezcla y se transfirió a un tubo que contenía $8 \mathrm{ml}$ de neutralizante y $1 \mathrm{ml}$ de agua. El tubo fue colocado en un baño de agua a $20^{\circ} \pm 1^{\circ} \mathrm{C}$ durante $5 \mathrm{~min}$. Se mezcló con vortex y se sembró $1 \mathrm{ml}$ por duplicado en agar TSA mediante la técnica de vertido en caja. Las cajas se incubaron 24 horas a $37^{\circ} \mathrm{C}$ para luego efectuar el recuento. Se realizaron 6 réplicas de cada ensayo.

\section{Control de las condiciones experimentales (Control A)}

Se dispensó $1 \mathrm{ml}$ de la sustancia interferente y $1 \mathrm{ml}$ de la suspensión de validación en un tubo. Luego de mezclar, se colocó el tubo en un baño de agua a la temperatura seleccionada durante $2 \mathrm{~min}$. Se añadieron $8 \mathrm{ml}$ de agua destilada estéril, se mezcló y se colocó el tubo en un baño de agua a la temperatura y tiempos seleccionados. Se mezcló y se inoculó $1 \mathrm{ml}$ de esta mezcla por duplicado mediante la técnica de vertido en caja. Las cajas se incubaron 24 horas a $37^{\circ} \mathrm{C}$ para luego efectuar el recuento. Se realizaron 6 réplicas de este control.

\section{Control del neutralizante (Control B)}

Se transfirieron $8 \mathrm{ml}$ del neutralizante (caldo Letheen) y $1 \mathrm{ml}$ de agua destilada estéril en un tubo. Se añadió $1 \mathrm{ml}$ de la suspensión de validación. Se mezcló y se colocó el tubo en un baño de agua a $20^{\circ} \pm 1^{\circ} \mathrm{C}$ durante $5 \mathrm{~min}$. Se mezcló, y se inoculó $1 \mathrm{ml}$ por duplicado utilizando la técnica de vertido en caja. Las cajas se incubaron 24 horas a $37^{\circ} \mathrm{C}$ para luego efectuar el recuento. Se realizaron 6 réplicas de este control.

\section{Control del método dilución-neutralización (Control C)}

Se pipeteó $1 \mathrm{ml}$ de la sustancia interferente y $1 \mathrm{ml}$ de diluyente en un tubo. Se añadieron $8 \mathrm{ml}$ de producto, se mezcló y se colocó el tubo en un baño de agua a la temperatura y tiempos seleccionados. Se mezcló y se transfirió $1 \mathrm{ml}$ de esta mezcla a un tubo con $8 \mathrm{ml}$ de neutralizante. Se colocó el tubo en un baño de agua a $20^{\circ} \pm 1^{\circ} \mathrm{C}$ durante $5 \mathrm{~min}$. Se añadió $1 \mathrm{ml}$ de la suspensión de validación, se mezcló y se colocó el tubo en un baño de agua a $20^{\circ} \pm 1^{\circ} \mathrm{C}$ durante $30 \mathrm{~min}$. Se mezcló y se inoculó $1 \mathrm{ml}$ de esta mezcla por duplicado utilizando la técnica de vertido en caja. Las cajas se incubaron 24 horas a $37^{\circ} \mathrm{C}$ para luego efectuar el recuento. Se realizaron 6 réplicas de este control.

\section{Verificación del método dilución- neutralización}

La verificación del método se realizó teniendo en cuenta el cumplimiento de los límites básicos estipulados en la norma y consignados en el numeral 5.7.3 de la misma.

\section{Resultados y discusión}

\section{Establecimiento de las condiciones experimentales para el método de ensayo dilución-neutralización}

Las condiciones experimentales establecidas por la norma no presentaron modificaciones, a excepción del tiempo de contacto de $60 \mathrm{~min}$, el cual fue omitido ya que las especificaciones del producto sugieren un tiempo de contacto corto para ejercer su acción bactericida. Se establecieron los tiempos de contacto 2, 5 y 10 minutos, luego de un ensayo preliminar que demostró que el producto ejercía acción bactericida en el menor tiempo de contacto ( 5 minutos). Las condiciones experimentales obligatorias y adicionales aplicadas en el ensayo se consignan en la figura 1 .

\section{Implementación y verificación del método de ensayo dilución-neutralización según la norma técnica colombiana 5473 del 2007}

\section{Preparación de la suspensión de ensayo y validación}

Se trabajó inicialmente con la cepa de Staphylococcus aureus ATCC 6538. Para esto se tomó como referencia el tubo $\mathrm{N}^{\mathrm{o}} 1$ del patrón de McFarland cuya concentración celular es equivalente a $3 \times 10^{8} \mathrm{UFC} / \mathrm{ml}$, para cumplir con las exigencias de la norma que determina que el recuento en esta suspensión debe ser entre $1,5 \times 10^{8} \mathrm{UFC} / \mathrm{ml}$ y $5,0 \times 10^{8}$ UFC/ml. La absorbancia fue calibrada a un valor de 0,2. Sin embargo, al realizar el recuento este fue de $4 \times 10^{9}$ por lo cual fue necesario preparar una suspensión nueva. De acuerdo con lo anterior, se sugirió trabajar la suspensión utilizando solución salina como diluyente omitiendo la adición de triptona, ya que se tenía como hipótesis que esto podría estar interfiriendo con la absorbancia propia de la suspensión, se prepararon dos suspensiones, una empleando únicamente solución salina como diluyente y la otra utilizando el diluyente especificado en la norma, es decir, solución salina más triptona. La absorbancia de ambas suspensiones fue similar al patrón de McFarland $(0,199)$. Los resultados de los recuentos reflejaron que efectivamente, 


\section{Condiciones experimentales}

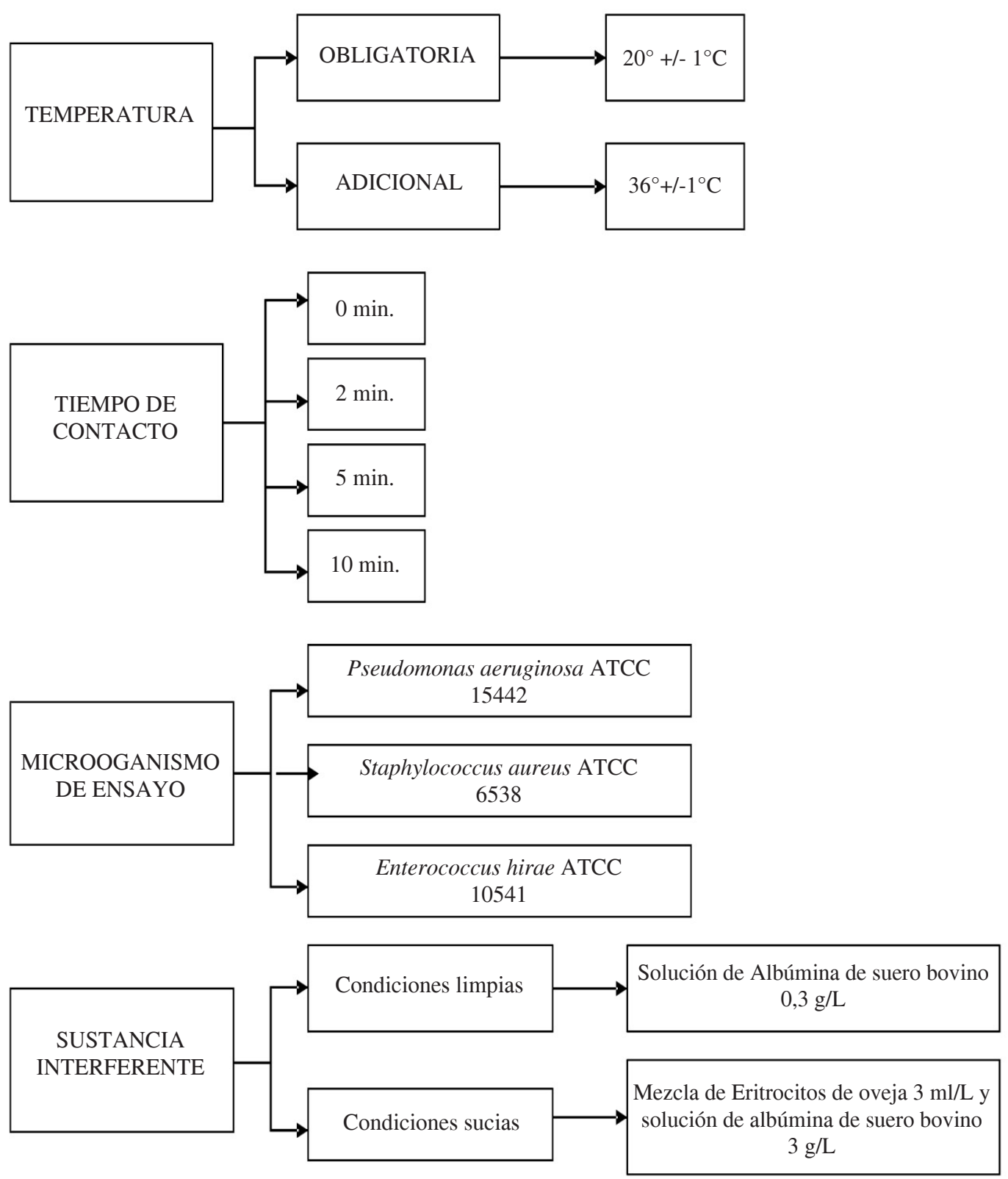

Figura 1. Condiciones experimentales obligatorias y adicionales aplicadas en el ensayo

la suspensión elaborada solo con solución salina cumplía con las especificaciones de la norma tabla 1 , mientras que el recuento de la suspensión elaborada con triptona excedía los requerimientos de la norma.

A partir de la suspensión de ensayo, se preparó la suspensión de validación, siguiendo las especificaciones de la norma, es decir a partir de una cuarta parte de la dilución $10^{-5}$ de la Suspensión de ensayo. Igualmente se utilizó como diluyente solución salina y el recuento fue adecuado para llevar a cabo el procedimiento (Tabla 2 ).

Al preparar la suspensión de Pseudomonas aeruginosa cepa ATCC 15442, siguiendo el procedimiento descrito para la suspensión de Staphylococcus aureus, se notó que la turbidez que proporcionaba una colonia de $P$. aeruginosa era mayor comparada con una colonia de S. aureus, posiblemente debido a que Pseudomonas aeruginosa es 
Tabla 1. Especificaciones de la Norma 5473 ICONTEC

Límites básicos establecidos por la NTC 5473 del ICONTEC.

\begin{tabular}{|c|c|c|c|}
\hline $\mathrm{N}$ & \multirow{4}{*}{ Esta comprendido entre } & $\begin{array}{l}1,5 \times 10^{8} \mathrm{UFC} / \mathrm{ml} \text { y } 5 \times 10^{8} \\
\mathrm{UFC} / \mathrm{ml}\end{array}$ & $8,17=\log N=8,70$ \\
\hline No & & $1,5 \times 10^{7} \mathrm{UFC} / \mathrm{ml}$ y $5 \times 10^{7} \mathrm{UFC} / \mathrm{ml}$ & $7,17=\log \mathrm{No}=7,70$ \\
\hline Nvo & & \multicolumn{2}{|l|}{$30 \mathrm{UFC} / \mathrm{ml}$ y $160 \mathrm{UFC} / \mathrm{ml}$} \\
\hline Nvo & & \multicolumn{2}{|l|}{$300 \mathrm{UFC} / \mathrm{ml}$ y $1600 \mathrm{UFC} / \mathrm{ml}$} \\
\hline $\mathrm{A}, \mathrm{B}, \mathrm{C}$ & \multicolumn{3}{|c|}{ Son iguales o superiores a 0,5 (Nvo) } \\
\hline \multicolumn{4}{|c|}{$\begin{array}{l}\text { Al menos una concentración debe demostrar un LOG R } \geq 5 \text { y al menos una concentración debe demostrar un Log } \\
\mathrm{R}<5\end{array}$} \\
\hline \multicolumn{4}{|c|}{ En el control de los recuentos de los valores medios ponderados el cociente no es inferior a 5 ni superior a 15} \\
\hline
\end{tabular}

un microorganismo formador de biopelículas. Este tipo de microorganismos son capaces de producir polisacáridos y glicoproteínas para formar agregados entre sí (5). Por esta razón, se ajustó la absorbancia a un valor medio $(0,16)$. Esta absorbancia emitió un recuento que permitió trabajar con esta suspensión y elaborar a partir de ella, la suspensión de validación (Tabla 2).

En otros estudios (6), se recomienda ajustar espectrofotométricamente la densidad de las suspensiones bacterianas a $620 \mathrm{~nm}$ de longitud de onda, para obtener una absorbancia de 0,2 a 0,3 para bacilos Gram-negativos y de 0,3 a 0,4 para cocos Gram-positivos, lo cual puede ser útil al momento de preparar una suspensión con un recuento comprendido entre 1 y $3 \times 10^{8} \mathrm{UFC} / \mathrm{ml}$.

Por otra parte, la preparación de la suspensión de la cepa de Enterococcus hirae, utilizando como referencia la absorbancia emitida por la suspensión de $S$. aureus $(0,19)$ al tratarse de microorganismos Gram-positivos con morfología microscópicamente similar, arrojó una absorbancia final de 0,18 . El recuento establecido fue el adecuado para trabajar con esta suspensión (Tabla 2).

\section{Evaluación de las condiciones experimentales (Control A)}

De acuerdo con la norma, los resultados de los recuentos obtenidos en los parámetros de control no deben ser menores a la mitad del recuento obtenido en cada parámetro al final del tiempo cero de contacto. Esta condición fue satisfactoria en este control, tal como se refleja en los resultados experimentales consignados en la tabla 3.
Tabla 2. UFC/ml en las suspensiones bacterianas de ensayo (n) y validación $\left(n_{v}\right)$. Concentraciones de los microorganismos utilizados, con recuentos entre $1,5 \times 10^{8} \mathrm{UFC} / \mathrm{ml}$ y $5,0 \times 10^{8} \mathrm{UFC} / \mathrm{ml}$

\begin{tabular}{lcccc}
\hline Microorganismo & \multicolumn{2}{c}{} & \multicolumn{2}{c}{$\mathbf{N}_{\mathbf{v}}$} \\
\hline & Limpio & Sucio & Limpio & Sucio \\
\hline P aeruginosa & $1,6 \times 10^{8}$ & $1,9 \times 10^{8}$ & $3,8 \times 10^{2}$ & $4,4 \times 10^{2}$ \\
\hline S. aureus & $1,8 \times 10^{8}$ & $1,5 \times 10^{8}$ & $4,2 \times 10^{2}$ & $3,9 \times 10^{2}$ \\
\hline E. hirae & $4,6 \times 10^{8}$ & $1,5 \times 10^{8}$ & $1,1 \times 10^{3}$ & $3 \times 10^{2}$ \\
\hline
\end{tabular}

Esto permitió determinar que las temperaturas trabajadas $\left(20^{\circ} \mathrm{C}\right.$ y $\left.36^{\circ} \mathrm{C}\right)$, los interferentes, y los tiempos de exposición, no inciden de forma negativa en el crecimiento de los microorganismos.

Los resultados fueron similares para los dos interferentes.

\section{Verificación de la ausencia de toxicidad del neutralizante (Control B).}

En este estudio se utilizó caldo Letheen que es un medio altamente nutritivo compuesto por lecitina y Tween 80, capaz de neutralizar o inhibir la acción de los componentes activos del desinfectante, en este caso alcohol, permitiendo la culminación de la reacción bactericida. 
Tabla 3. Parámetro A: control de las condiciones experimentales seleccionadas.

\begin{tabular}{|c|c|c|c|c|c|c|c|c|c|c|c|c|c|c|c|c|}
\hline \multirow{3}{*}{ 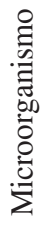 } & \multicolumn{16}{|c|}{ CONTROL A } \\
\hline & \multicolumn{8}{|c|}{ LIMPIO } & \multicolumn{8}{|c|}{ SUCIO } \\
\hline & $\begin{array}{l}0 \mathrm{~min} / \\
20^{\circ} \mathrm{C}\end{array}$ & $\begin{array}{c}0 \mathrm{~min} / \\
36^{\circ} \mathrm{C}\end{array}$ & $\begin{array}{l}2 \mathrm{~min} / \\
20^{\circ} \mathrm{C}\end{array}$ & $\begin{array}{l}2 \mathrm{~min} / \\
36^{\circ} \mathrm{C}\end{array}$ & $\begin{array}{c}5 \mathrm{~min} / \\
20^{\circ} \mathrm{C}\end{array}$ & $\begin{array}{l}5 \mathrm{~min} / \\
36^{\circ} \mathrm{C}\end{array}$ & $\begin{array}{l}10 \mathrm{~min} / \\
20^{\circ} \mathrm{C}\end{array}$ & $\begin{array}{c}10 \mathrm{~min} / \\
36^{\circ} \mathrm{C}\end{array}$ & $\begin{array}{l}0 \mathrm{~min} / \\
20^{\circ} \mathrm{C}\end{array}$ & $\begin{array}{l}0 \mathrm{~min} / \\
36^{\circ} \mathrm{C}\end{array}$ & $\begin{array}{l}2 \mathrm{~min} / \\
20^{\circ} \mathrm{C}\end{array}$ & $\begin{array}{l}2 \mathrm{~min} / \\
36^{\circ} \mathrm{C}\end{array}$ & $\begin{array}{l}5 \mathrm{~min} / \\
20^{\circ} \mathrm{C}\end{array}$ & $\begin{array}{l}5 \mathrm{~min} / \\
36^{\circ} \mathrm{C}\end{array}$ & $\begin{array}{c}10 \mathrm{~min} / \\
20^{\circ} \mathrm{C}\end{array}$ & $\begin{array}{c}10 \mathrm{~min} / \\
36^{\circ} \mathrm{C}\end{array}$ \\
\hline \multirow{6}{*}{ 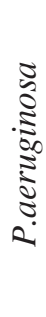 } & 32 & 36 & 30 & 28 & 27 & 19 & 16 & 16 & 37 & 39 & 22 & 28 & 24 & 25 & 20,5 & 26 \\
\hline & 34 & 32 & 28 & 30 & 28 & 21 & 19 & 21 & 35,5 & 36,5 & 25 & 27,5 & 21 & 22,5 & 26 & 26 \\
\hline & 30 & 30 & 32 & 35 & 32 & 18 & 19 & 15 & 34 & 30 & 27 & 20,5 & 27 & 26 & 19 & 22 \\
\hline & 36 & 31 & 32 & 34 & 30 & 16 & 16 & 21 & 32 & 33 & 21 & 23 & 19 & 28 & 25 & 24,5 \\
\hline & 38 & 38 & 30 & 30 & 32 & 24 & 14 & 24 & 33,5 & 32,5 & 20 & 22,5 & 24 & 28 & 22 & 28 \\
\hline & 36 & 34 & 28 & 33 & 27 & 21 & 21 & 23 & 35 & 30 & 23,5 & 38,5 & 22,5 & 24,5 & 24,5 & 24,5 \\
\hline \multirow{6}{*}{$\begin{array}{c}\tilde{3} \\
\vdots \\
\vdots \\
\vdots \\
\dot{3}\end{array}$} & 34,5 & 28,5 & 37 & 24,5 & 21,5 & 25 & 28,5 & 25 & 34 & 32 & 30,5 & 37 & 35,5 & 41,5 & 31,5 & 40,5 \\
\hline & 33 & 34 & 33 & 23 & 18 & 22,5 & 23 & 26 & 36 & 32,5 & 35 & 33 & 37,5 & 34 & 35 & 34 \\
\hline & 37 & 36 & 37 & 24,5 & 28,5 & 21,5 & 18 & 30 & 32 & 32 & 39 & 31,5 & 36,5 & 38 & 34 & 31,5 \\
\hline & 38,5 & 36 & 33,5 & 22,5 & 24 & 24,5 & 23 & 24 & 31 & 38 & 32 & 35 & 34,5 & 35,5 & 39 & 30,5 \\
\hline & 38 & 32,5 & 39 & 21,5 & 29 & 25,5 & 18 & 24 & 34,5 & 39 & 33 & 35 & 34,5 & 30 & 35 & 32 \\
\hline & 32 & 37 & 30 & 23,5 & 20 & 22,5 & 23 & 23 & 30,5 & 30 & 33 & 38 & 40 & 31 & 34,5 & 35 \\
\hline \multirow{6}{*}{$\underset{\mathbb{1}}{\stackrel{\Xi}{\approx}}$} & 116 & 102 & 96 & 106,5 & 121 & 98 & 113,5 & 123 & 23 & 29,5 & 24,5 & 28,5 & 24 & 26 & 23 & 31 \\
\hline & 101 & 128 & 100 & 118 & 116 & 114 & 115 & 111,5 & 24 & 28,5 & 24,5 & 27,5 & 25 & 27 & 25 & 27,5 \\
\hline & 100 & 112,5 & 113 & 118 & 108,5 & 116,6 & 110 & 105 & 27 & 24 & 24,5 & 28 & 23 & 26,5 & 22,5 & 25,5 \\
\hline & 114 & 106 & 125 & 109 & 112 & 127 & 131 & 96 & 26 & 25 & 25 & 27,5 & 26 & 28 & 22,5 & 25,5 \\
\hline & 110 & 105,5 & 125 & 121 & 115 & 120,5 & 111 & 114 & 27 & 26,5 & 23 & 30 & 22 & 28 & 25 & 30 \\
\hline & 104 & 110 & 114,5 & 103,5 & 122,5 & 111 & 106 & 102 & 26,5 & 29,5 & 25,5 & 31,5 & 24 & 29 & 24 & 28 \\
\hline
\end{tabular}

Los datos recopilados en la tabla 4, muestran que el neutralizante permitió ampliamente el crecimiento de los microorganismos evaluados, y no presentó efectos negativos que llegaran a ocasionar inhibición en los mismos.

\section{Validación del método Dilución Neutralización (Control C)}

De igual manera que en los demás controles, el recuento de todas las replicas en los diferentes tiempos y temperaturas evaluados, fue superior a la mitad del recuento obtenido en el parámetro al final del tiempo de contacto cero, para los tres microorganismos y las dos condiciones de limpieza simuladas (Tabla 5).

Este parámetro de control permitió determinar que el método está diseñado para conocer la acción bactericida de cualquier
Tabla 4. Parámetro B: control del neutralizante (verificación de la ausencia de toxicidad del neutralizante)

\begin{tabular}{|c|c|}
\hline Microorganismo & Control B \\
\hline \multirow{6}{*}{ P. aeruginosa } & 33 \\
\hline & 36 \\
\hline & 34,5 \\
\hline & 32 \\
\hline & 34 \\
\hline & 37 \\
\hline \multirow{6}{*}{ S. aureus } & 39 \\
\hline & 38 \\
\hline & 39 \\
\hline & 37 \\
\hline & 36 \\
\hline & 40 \\
\hline \multirow{6}{*}{ E. hirae } & 111 \\
\hline & 93,5 \\
\hline & 106,5 \\
\hline & 117 \\
\hline & 118 \\
\hline & 120 \\
\hline
\end{tabular}


desinfectante sin generar por si mismo efectos negativos sobre el microorganismo control.

\section{Ensayo NA - método dilución neutralización}

Las suspensiones de ensayo de cada uno de los microorganismos control propuestos en la norma se enfrentaron al desinfectante para manos en gel a una concentración final de ensayo de $80 \%$ del producto.

El comportamiento de cada cepa evaluada fue diferente. La cepa de $S$. aureus sólo presentó crecimiento en el tiempo 0, el cual fue mayor a 330 que fue el límite máximo establecido por la norma (Tabla 6). Esto debido a que en este tiempo, el desinfectante es neutralizado inmediatamente después de la adición del microorganismo, impidiendo que haya un tiempo de contacto suficiente entre el desinfectante y la suspensión.

En los demás tiempos evaluados no se presentó crecimiento del microorganismo, con lo cual se comprueba que el desinfectante es capaz de actuar desde 2 minutos de contacto. Estos resultados están de acuerdo con los resultados establecidos en estudios anteriores (7), en el cual concentraciones mínimas de etanol causan ruptura celular y cambios irregulares en la apariencia de las mismas, así como afección en la función de la membrana celular, interferencia en la división celular, afección en el crecimiento, variación en la composición de los ácidos grasos y en la síntesis de proteínas e inhibición en el transporte de nutrientes a la célula.

Por otra parte, $P$. aeruginosa mostró crecimiento leve en todos los tiempos excepto en el tiempo 0 en el que el recuento en todas la replicas fue mayor a 330 (Tabla 6). Debido a que en las replicas de los tiempos 2,5 y 10 los recuentos oscilaron entre10 y 15 colonias, se tomaron como menores a catorce por especificación de la norma, lo que permitió obtener valores $\mathrm{Na}$ menores a 140. La resistencia de $P$. aeruginosa es atribuida a varios factores que han sido consignados en diversos estudios (8), estableció que las bacterias Gram-negativas poseen reducida sensibilidad hacia los desinfectantes comparadas con los estafilococos debido a los lipopolisacaridos de su membrana externa que impiden el flujo de los desinfectantes al interior de la célula.

Por otra parte (9), estableció que $P$. aeruginosa es capaz de crecer en etanol e inducir enzimas capaces de oxidarlo y metabolizarlo a acetato.

Se esperaba que E. hirae, se comportara de manera similar al del microorganismo $S$. aureus por la similitud en morfología y coloración que existe entre estos dos microorganismos. Sin embargo, E. hirae a diferencia de $S$. aureus presentó crecimiento en los tiempos 2, 5 y 10 de los ambos interferentes. Sin embargo, aunque presentó crecimiento, el número de colonias fue menor a 12 por lo cual se consideró la especificación de la norma y se reportó el resultado como menor a 140 .

Según el estudio realizado por (10), los enterococos son importantes patógenos nosocomiales cuyo factor de virulencia importante es su resistencia intrínseca y adquirida a muchos agentes antimicrobianos; esto podría explicar el crecimiento de la cepa de E. hirae, en los tiempos de contacto 2,5 y $10 \mathrm{~min}$.

En síntesis, el empleo de desinfectantes en gel cuyo principio activo es alcohol, pueden constituir un mecanismo importante de desinfección de manos en el ámbito hospitalario, y para que su efecto sea notorio en bacterias Gram-negativas y otros microorganismos de difícil eliminación se puede aumentar la concentración de alcohol al tiempo que se manejen emolientes que eviten el daño a la piel pero no interfieran en la acción bactericida del desinfectante.

\section{Verificación de la metodología}

Se llevó a cabo de acuerdo con los numerales 5,7 y 5,8 de la NTC 5473 del ICONTEC, mediante la comparación de la media aritmética de las replicas de los resultados obtenidos con los límites básicos establecidos por la norma. El parámetro de aceptación de la Norma es que al menos una concentración debe demostrar un LOG R $\geq 5$ y al menos una concentración debe demostrar un $\log \mathrm{R}<5$

\section{Recolección de la información}

Para recolectar la información se emplearon los parámetros establecidos por la norma técnica colombiana 5473 a partir de la cual se tuvo en cuenta los procedimientos experimentales para la determinación de la actividad bactericida del desinfectante empleado.

Además se obtuvo información partir de consulta bibliográfica con el fin de determinar los mecanismos de acción del proceso de desinfección y su aplicación en instrumental médico.

Para la recopilación de los datos experimentales se empleó una matriz en la cual se registraron los resultados obtenidos en cada una de las replicas a las condiciones de 38 tiempo, temperatura, tipo de microorganismo, interferente y concentración de los desinfectantes evaluados. 
Por otra parte se emplearon tablas en la cual se registraron los resultados obtenidos a partir del conteo de células/ ml en cada uno de los ensayos y en los controles realizados.

\section{Análisis de información}

Inicialmente se hizo una determinación de los valores $\mathrm{Vc}$, que son los valores experimentales que se obtuvieron en el método de dilución-neutralización. Estos valores incluyen los valores de ensayo y los controles.

En el método de dilución-neutralización se tuvo en cuenta valores Vc entre un límite entre 14y 130 colonias. Para el cálculo del número de células/ $\mathrm{ml}$ de la suspensión de ensayo se calculó la media aritmética ponderada de los recuentos de dos diluciones escogidas de esta suspensión. Para esto se utilizara la siguiente fórmula:

$$
N=\frac{C}{(n 1+0,1 n 2) 10^{-6}}
$$

\section{Donde:}

$C$ es la suma de los valores $\mathrm{Vc}$ tenidos en cuenta; $n 1$ es el numero de los valores $\mathrm{Vc}$ tenidos en cuenta en la dilución inferior, es decir $\left(10^{-6}\right)$;

$n 2$ es el numero de valores Vc tenidos en cuenta en la segunda dilución, es decir $\left(10^{-7}\right)$;

$10^{-6}$ es el factor de dilución correspondiente a la dilución inferior.

Para determinar el número de células/ml en la mezcla de ensayo al comienzo del tiempo de contacto (No) es decir, al tiempo cero, se obtuvo la decima parte de la media aritmética

Tabla 5. Parámetro c: validación del método de dilución neutralización.

\begin{tabular}{|c|c|c|c|c|c|c|c|c|c|c|c|c|c|c|c|c|}
\hline \multirow{3}{*}{ 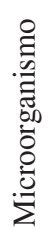 } & \multicolumn{16}{|c|}{ Control C } \\
\hline & \multicolumn{8}{|c|}{ Limpio } & \multicolumn{8}{|c|}{ Sucio } \\
\hline & $\begin{array}{c}0 \\
\mathrm{~min} / \\
20^{\circ} \mathrm{C}\end{array}$ & $\begin{array}{c}0 \\
\mathrm{~min} / \\
36^{\circ} \mathrm{C}\end{array}$ & $\begin{array}{c}2 \\
\mathrm{~min} / \\
20^{\circ} \mathrm{C}\end{array}$ & $\begin{array}{c}2 \\
\mathrm{~min} / \\
36^{\circ} \mathrm{C}\end{array}$ & $\begin{array}{c}5 \\
\mathrm{~min} / \\
20^{\circ} \mathrm{C}\end{array}$ & $\begin{array}{c}5 \\
\mathrm{~min} / \\
36^{\circ} \mathrm{C}\end{array}$ & $\begin{array}{c}10 \\
\mathrm{~min} / \\
20^{\circ} \mathrm{C}\end{array}$ & $\begin{array}{c}10 \\
\mathrm{~min} / \\
36^{\circ} \mathrm{C}\end{array}$ & $\begin{array}{c}0 \\
\mathrm{~min} / \\
20^{\circ} \mathrm{C}\end{array}$ & $\begin{array}{c}0 \\
\mathrm{~min} / \\
36^{\circ} \mathrm{C}\end{array}$ & $\begin{array}{c}2 \\
\mathrm{~min} / \\
20^{\circ} \mathrm{C}\end{array}$ & $\begin{array}{c}2 \\
\mathrm{~min} / \\
36^{\circ} \mathrm{C}\end{array}$ & $\begin{array}{c}5 \\
\mathrm{~min} / \\
20^{\circ} \mathrm{C}\end{array}$ & $\begin{array}{c}5 \\
\mathrm{~min} / \\
36^{\circ} \mathrm{C}\end{array}$ & $\begin{array}{c}10 \\
\mathrm{~min} / \\
20^{\circ} \mathrm{C}\end{array}$ & $\begin{array}{c}10 \\
\mathrm{~min} / \\
36^{\circ} \mathrm{C}\end{array}$ \\
\hline \multirow{6}{*}{ 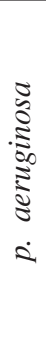 } & 38 & 37 & 36,5 & 28,5 & 32 & 34,5 & 34 & 37,5 & 31,5 & 33,5 & 30,5 & 31,5 & 34,5 & 35 & 38,5 & 33,5 \\
\hline & 32 & 36,5 & 32,5 & 31 & 28,5 & 37,5 & 40,5 & 36 & 33,5 & 38 & 38 & 37 & 32 & 39 & 30 & 36 \\
\hline & 35,5 & 40 & 39 & 29 & 34 & 32 & 36 & 38 & 34 & 33,5 & 40,5 & 38,5 & 34,5 & 39 & 30 & 35 \\
\hline & 37 & 33 & 4 & 32 & 36,5 & 34,5 & 37 & 33,5 & 30,5 & 32 & 38 & 36 & 31 & 37 & 34 & 30,5 \\
\hline & 31,5 & 31,5 & 33,5 & 39 & 40 & 33 & 31,5 & 31,5 & 37 & 38 & 37,5 & 37,5 & 31,5 & 37 & 30 & 32,5 \\
\hline & 30 & 34 & 31,5 & 37,5 & 33,5 & 30 & 33 & 36 & 33 & 35 & 35,5 & 34 & 30 & 38 & 30 & 33 \\
\hline \multirow{6}{*}{ 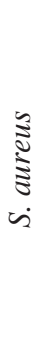 } & 48,5 & 32 & 42,5 & 35 & 40,5 & 32 & 47,5 & 35,5 & 40,5 & 34,5 & 33,5 & 36,5 & 33 & 34,5 & 38,5 & 38,5 \\
\hline & 43,5 & 35,5 & 37,5 & 41,5 & 49 & 39,5 & 39 & 37 & 35,5 & 33,5 & 33,5 & 36,5 & 37 & 37,5 & 38,5 & 40,5 \\
\hline & 40 & 32 & 43 & 35,5 & 55 & 34,5 & 42 & 34 & 36 & 36,5 & 35,5 & 31,5 & 35,5 & 35 & 38 & 35 \\
\hline & 37 & 32,5 & 39 & 41,5 & 42,5 & 30,5 & 54 & 43,5 & 35,5 & 42 & 32,5 & 40,5 & 36 & 34 & 38,5 & 38 \\
\hline & 40,5 & 36 & 38 & 34,5 & 44,5 & 37 & 46 & 39 & 37,5 & 34 & 37 & 38,5 & 33 & 33,5 & 34,5 & 32,5 \\
\hline & 39,5 & 35,5 & 34,5 & 32,5 & 49 & 34 & 48,5 & 38,5 & 34 & 39 & 36,5 & 34,5 & 41 & 37,5 & 36 & 30 \\
\hline \multirow{6}{*}{ 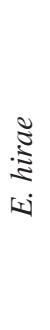 } & 93,5 & 115,5 & 95 & 114 & 111,5 & 95,5 & 95 & 105,5 & 28 & 28,5 & 32,5 & 24 & 26,5 & 30,5 & 26 & 27 \\
\hline & 96,5 & 117 & 95,5 & 114,5 & 107 & 98 & 95,5 & 109 & 23,5 & 24,5 & 25,5 & 27,5 & 26 & 25,5 & 25 & 26,5 \\
\hline & 99 & 108,5 & 128,5 & 100,5 & 108,5 & 109,5 & 128,5 & 9. & 33,5 & 27,5 & 26 & 25,5 & 23,5 & 24 & 23,5 & 24,5 \\
\hline & 119,5 & 101 & 105 & 94 & 125 & 98,5 & 105 & 102 & 25,5 & 28 & 29,5 & 29 & 27 & 27,5 & 25,5 & 24 \\
\hline & 122 & 99,5 & 115,5 & 113,5 & 119 & 102 & 115,5 & 100,5 & 24 & 24,5 & 29 & 25,5 & 26 & 25 & 27 & 27 \\
\hline & 126,5 & 112 & 127 & 95,5 & 127,5 & 105,5 & 127 & 97,5 & 25 & 28,5 & 25,5 & 25,5 & 23,5 & 26 & 24 & 25,5 \\
\hline
\end{tabular}


Tabla 6. Ensayo na: determinación de la actividad bactericida del producto.

\begin{tabular}{|c|c|c|c|c|c|c|c|c|c|c|c|c|c|c|c|c|}
\hline \multirow{3}{*}{ 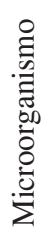 } & \multicolumn{16}{|c|}{ Ensayo } \\
\hline & \multicolumn{8}{|c|}{ Limpio } & \multicolumn{8}{|c|}{ Sucio } \\
\hline & $\begin{array}{c}0 \\
\mathrm{~min} / \\
20^{\circ} \mathrm{C}\end{array}$ & $\begin{array}{c}0 \\
\mathrm{~min} / \\
36^{\circ} \mathrm{C}\end{array}$ & $\begin{array}{c}2 \\
\mathrm{~min} / \\
20^{\circ} \mathrm{C}\end{array}$ & $\begin{array}{c}2 \\
\mathrm{~min} / \\
36^{\circ} \mathrm{C}\end{array}$ & $\begin{array}{c}5 \\
\min / \\
20^{\circ} \mathrm{C}\end{array}$ & $\begin{array}{c}5 \\
\mathrm{~min} / \\
36^{\circ} \mathrm{C}\end{array}$ & $\begin{array}{c}10 \mathrm{~min} \\
20^{\circ} \mathrm{C}\end{array}$ & $\begin{array}{c}10 \\
\min / \\
36^{\circ} \mathrm{C}\end{array}$ & $\begin{array}{c}0 \\
\mathrm{~min} / \\
20^{\circ} \mathrm{C}\end{array}$ & $\begin{array}{c}0 \\
\mathrm{~min} / \\
36^{\circ} \mathrm{C}\end{array}$ & $\begin{array}{c}2 \\
\mathrm{~min} / \\
20^{\circ} \mathrm{C}\end{array}$ & $\begin{array}{c}2 \\
\min / \\
36^{\circ} \mathrm{C}\end{array}$ & $\begin{array}{c}5 \\
\mathrm{~min} / \\
20^{\circ} \mathrm{C}\end{array}$ & $\begin{array}{c}5 \\
\min / \\
36^{\circ} \mathrm{C}\end{array}$ & $\begin{array}{c}10 \mathrm{~min} \\
20^{\circ} \mathrm{C}\end{array}$ & $\begin{array}{c}10 \mathrm{~min} / \\
36^{\circ} \mathrm{C}\end{array}$ \\
\hline \multirow{6}{*}{ 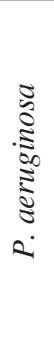 } & $>330$ & $>330$ & $<14$ & $<14$ & $<14$ & $<14$ & $<14$ & $<14$ & $>330$ & $>330$ & $<14$ & $<14$ & $<14$ & $<14$ & $<14$ & $<14$ \\
\hline & $>330$ & $>330$ & $<14$ & $<14$ & $<14$ & $<14$ & $<14$ & $<14$ & $>330$ & $>330$ & $<14$ & $<14$ & $<14$ & $<14$ & $<14$ & $<14$ \\
\hline & $>330$ & $>330$ & $<14$ & $<14$ & $<14$ & $<14$ & $<14$ & $<14$ & $>330$ & $>330$ & $<14$ & $<14$ & $<14$ & $<14$ & $<14$ & $<14$ \\
\hline & $>330$ & $>330$ & $<14$ & $<14$ & $<14$ & $<14$ & $<14$ & $<14$ & $>330$ & $>330$ & $<14$ & $<14$ & $<14$ & $<14$ & $<14$ & $<14$ \\
\hline & $>330$ & $>330$ & $<14$ & $<14$ & $<14$ & $<14$ & $<14$ & $<14$ & $>330$ & $>330$ & $<14$ & $<14$ & $<14$ & $<14$ & $<14$ & $<14$ \\
\hline & $>330$ & $>330$ & $<14$ & $<14$ & $<14$ & $<14$ & $<14$ & $<14$ & $>330$ & $>330$ & $<14$ & $<14$ & $<14$ & $<14$ & $<14$ & $<14$ \\
\hline \multirow{6}{*}{ 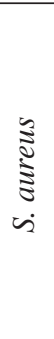 } & $>330$ & $>330$ & $<14$ & $<14$ & $<14$ & $<14$ & $<14$ & $<14$ & $>330$ & $>330$ & $<14$ & $<14$ & $<14$ & $<14$ & $<14$ & $<14$ \\
\hline & $>330$ & $>330$ & $<14$ & $<14$ & $<14$ & $<14$ & $<14$ & $<14$ & $>330$ & $>330$ & $<14$ & $<14$ & $<14$ & $<14$ & $<14$ & $<14$ \\
\hline & $>330$ & $>330$ & $<14$ & $<14$ & $<14$ & $<14$ & $<14$ & $<14$ & $>330$ & $>330$ & $<14$ & $<14$ & $<14$ & $<14$ & $<14$ & $<14$ \\
\hline & $>330$ & $>330$ & $<14$ & $<14$ & $<14$ & $<14$ & $<14$ & $<14$ & $>330$ & $>330$ & $<14$ & $<14$ & $<14$ & $<14$ & $<14$ & $<14$ \\
\hline & $>330$ & $>330$ & $<14$ & $<14$ & $<14$ & $<14$ & $<14$ & $<14$ & $>330$ & $>330$ & $<14$ & $<14$ & $<14$ & $<14$ & $<14$ & $<14$ \\
\hline & $>330$ & $>330$ & $<14$ & $<14$ & $<14$ & $<14$ & $<14$ & $<14$ & $>330$ & $>330$ & $<14$ & $<14$ & $<14$ & $<14$ & $<14$ & $<14$ \\
\hline \multirow{6}{*}{ 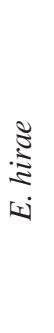 } & $>330$ & $>330$ & $<14$ & $<14$ & $<14$ & $<14$ & $<14$ & $<14$ & $>330$ & $>330$ & $<14$ & $<14$ & $<14$ & $<14$ & $<14$ & $<14$ \\
\hline & $>330$ & $>330$ & $<14$ & $<14$ & $<14$ & $<14$ & $<14$ & $<14$ & $>330$ & $>330$ & $<14$ & $<14$ & $<14$ & $<14$ & $<14$ & $<14$ \\
\hline & $>330$ & $>330$ & $<14$ & $<14$ & $<14$ & $<14$ & $<14$ & $<14$ & $>330$ & $>330$ & $<14$ & $<14$ & $<14$ & $<14$ & $<14$ & $<14$ \\
\hline & $>330$ & $>330$ & $<14$ & $<14$ & $<14$ & $<14$ & $<14$ & $<14$ & $>330$ & $>330$ & $<14$ & $<14$ & $<14$ & $<14$ & $<14$ & $<14$ \\
\hline & $>330$ & $>330$ & $<14$ & $<14$ & $<14$ & $<14$ & $<14$ & $<14$ & $>330$ & $>330$ & $<14$ & $<14$ & $<14$ & $<14$ & $<14$ & $<14$ \\
\hline & $>330$ & $>330$ & $<14$ & $<14$ & $<14$ & $<14$ & $<14$ & $<14$ & $>330$ & $>330$ & $<14$ & $<14$ & $<14$ & $<14$ & $<14$ & $<14$ \\
\hline
\end{tabular}

ponderada de $\mathrm{N}$ (número de células/ml en la suspensión de ensayo) debido a que por la adición del producto y de la sustancia interferente se obtiene una dilución a la decima parte.

Para la determinación del número de microorganismos supervivientes/ml en la mezcla de ensayo al final del tiempo de contacto y antes de la neutralización ( $\mathrm{Na}$ ), se empleó la siguiente fórmula:

$$
\begin{gathered}
N_{a}=\frac{C X 10}{n} \\
N_{v o}=\frac{C}{n}
\end{gathered}
$$

\section{Donde:}

$C$ es la suma de los valores $V c$ tenidos en cuenta $n$ es el número de valores $V c$ tenidos en cuenta.
Para calcular el número de sobrevivientes en el control de las condiciones experimentales (tiempo, temperatura, sustancia interferente), control del neutralizante y estandarización del método al final del tiempo de contacto, se empleó la siguiente fórmula:

$$
A, B, C=\frac{C}{n}
$$

\section{Donde:}

$c$ es la suma de los valores $V c$ tenidos en cuenta;

$n$ es el número de valores $V c$ tenidos en cuenta

La tabulación de los datos se hizo teniendo en cuenta la matriz de resultados relacionando lo obtenido en cada uno de los ensayo con las condiciones experimentales trabajadas. 


\section{Conclusiones}

Se determinó que las condiciones experimentales del ensayo deben establecerse teniendo en cuenta las condiciones reales a las que se verá sometido el desinfectante a evaluar; para este fin, deben tenerse en cuenta las especificaciones del fabricante, el principio activo del desinfectante, su presentación e incluso el lugar donde se va a utilizar. Los resultados obtenidos en este estudio elucidan que el método dilución neutralización de la NTC 5473, resulta confiable para evaluar la actividad bactericida de un desinfectante. De este modo, la norma garantiza a quien emplee su método dilución neutralización, la consecución de resultados confiables y el control de los parámetros que pudieran tener un efecto letal sobre los microorganismos de la prueba. Mediante el análisis de los resultados obtenidos en el ensayo y en los parámetros de control se determinó que no se generan inhibiciones del crecimiento bacteriano por motivos diferentes a la acción del producto a evaluar, tal como la metodología, las condiciones experimentales y la sustancia neutralizante. La elaboración del informe del ensayo permitió reportar y verificar los resultados obtenidos, comparándolos con los límites exigidos por la norma en pro de determinar su validez. Se encontró que el diluyente citado en la norma para la preparación de las suspensiones de ensayo y validación, puede interferir con la lectura de la absorbancia; además, si la suspensión de ensayo cumple con la absorbancia teórica del patrón número 1 de Mc Farland, al utilizar la cuarta parte de la dilución $10^{-5}$ de la suspensión de ensayo, el recuento de la suspensión de validación cumple con el rango de especificación de la norma.

Para la preparación de la suspensión de ensayo de $P$. aeruginosa y E. hirae, es preferible, ajustar la suspensión a una concentración alta (absorbancia de $620 \mathrm{~nm}$ ) y realizar el recuento, el cual servirá para preparar las suspensiones por el método de dilución.

\section{Financiación}

Este trabajo fue financiado por Laboratorios Vicar de Colombia

\section{Conflicto de intereses}

Los autores manifiestan no tener conflicto de intereses

\section{Referencias}

1. Ayliffe G A J, Fraise A P, Geddes A M, Mitchell K, eds. Control of Hospital Infection A Practical Handbook. 4th edition. Oxford: Arnold, 2000

2. Steer Jane. Decontamination. Surgery Medicine Publishing 2002; 20 (8): 197-200

3. Sterilization, Disinfection, and Cleaning of Medical Equipment: Guidance on Decontamination from the Microbiology Advisory Committee to the Department of Health. London: Medical Devices Agency, 1996.

4. Norma Técnica Colombiana 5473. 2007 Instituto Colombiano de Normas Técnicas y Certificación Icontec Bogotá Colombia 44p

5. Wirtanen G, Salo S, Helander IM, Mattila T. Microbiological methods for testing disinfectants efficiency on Pseudomonas biofilm. Colloids and Surfaces 2001; 20: 37-50.

6. Espigares E, Bueno A, Fernández-Crehuet M, Espigares M. Efficacy of some neutralizers in suspension tests determining the activity of disinfectants. Journal of Hospital Infection 2003; 55(2):137-140

7. Chatterjee I, Somerville GA, Heilmann C, Sahl H, Maurer HH, Herrmann M. Very low etanol concentrations affect the viability and growth recovery in post-stationaryphase Staphylococcus aureus populations. Applied and E nvironmental Microbiology 2006; 72 (4): 2627- 2636.

8. Russell AD. Bacterial resistance to disinfectants: present knowledge and future problems. Journal of Hospital Infection 1998; 43:57-68.

9. Görisch $\mathrm{H}$. The etanol oxidation system and its regulation in Pseudomonas aeruginosa. Biochimica et Biophysica Acta 2003; 1647(1-2):98-102

10. Sakagami Y, Kajimura K. Bactericidal activities of disinfectants against vancomycin-resistant enterococci. Journal of Hospital Infection 2002; 50 (2): 140-4. 